\title{
Structure in Art Practice: Technology as an Agent for Concept Development
}

\author{
Ernest Edmonds
}

\section{I}

t could be said that I am trying to understand how to generate interesting works. Aesthetic understanding, if we put it in these terms, comes not in understanding, for example, the color patches used in a work, but in understanding the underlying laws that led to their selection.

The notion of structure is used often in Systems Art in the U.K. Stephen Bann relates this concept to a linguistic one:

It is not the recurrence of the rectangle in Van Doesburg's work which needs to engage us, but the series of relationships between rectangles and the extent to which those relationships can be adequately formalised [1].

\section{AN OVERVIEW OF CONCEPTUAL DEVELOPMENTS}

At the center of my current art practice is time-based digital video work: video constructs. At the beginning of my practice, my only use of the computer was to solve problems. Interactivity was another early concern. Later, my emphasis changed to the use of computers as part of the final work, which was delivered on screens. Video projection followed, and since then, I have developed other forms of presentation and also incorporated music. The exhibition Constructs and ReConstructions provided a survey of the work and formed the basis for this paper [2].

In practice, my enterprise began in 1969. I had recently seen an exhibition of Charles Biederman's work in London and studied it in more detail when it moved to Leicester, where I lived [3]. One particular outcome of this experience was to focus my attention on the problem of limiting the variables that I was trying to manipulate. Following this, in order to try to understand what I had been doing in the previous decade, I made the piece Nineteen (Fig. 1), which brought the images and attributes of the decade's work together. Thus, a variety of elements had to co-exist in a single work. I introduced certain organizing principles and tried to apply them to the task of handling that co-existence. A "solution" was hard to find, until I noticed that the problem was quite similar to one that I had recently faced in mathematical logic. In that case, I had solved it by writing a computer program to do the searching for me, resulting in a short paper that I had published in the

Ernest Edmonds (artist, researcher), Creativity \& Cognition Research Studios, Department of Computer Science, Loughborough University, Loughborough, U.K. E-mail: <ernest@ernestedmonds.org.uk>.

An earlier version of this paper was presented at the third Creativity and Cognition Conference, Loughborough University, U.K., 10-13 October 1999, and published in the Proceedings (New York: ACM Press, 1999; ISBN: 1-58113-078-3).
Journal of Symbolic Logic [4]. Applying the same method, but using much more computer time, I completed the composition of Nineteen. The piece served its purpose in my explorations but was, unfortunately, destroyed during the removal of an exhibition in which it was included. However, I had achieved my first use of a computer in my art practice as a problem solver.

Directly arising from this work was a much simpler piece that concentrated on the organizing principles and constraints arising from the co-existence of different elements, such as an edge at a given angle. The work was Jigsaw (Fig. 2), and its novel feature was that its elements were rearrangeable. While shown, therefore, this work changed in time, within the constraints of the structuring rules, which were, in this case, imposed by the physical construction of the piece. I also explored film at this time, but I only produced an experimental study, which I showed privately. Participation and interaction also became significant for me at that time [5]. One particular form of interaction I explored was that between people through electronic net-

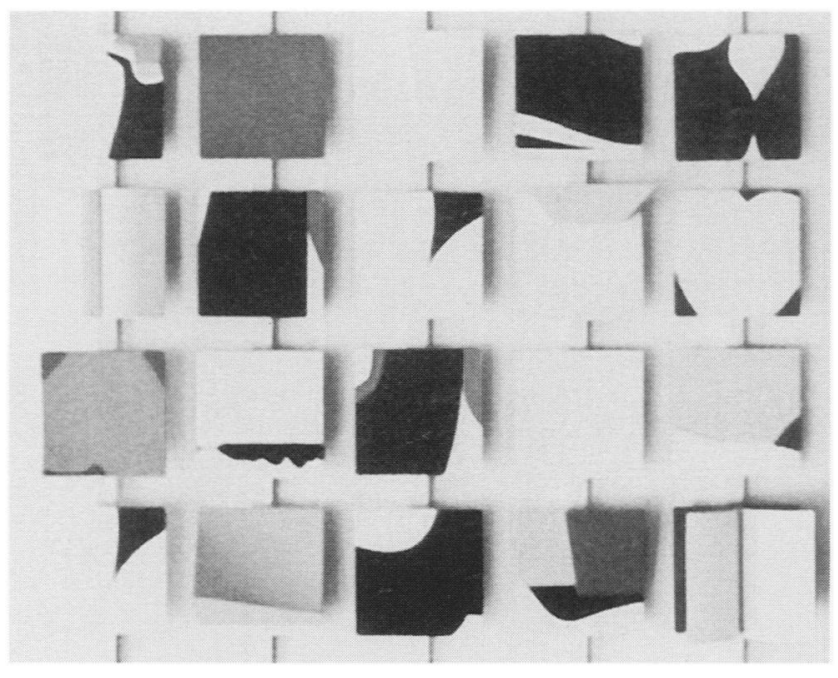

Fig. 1. Nineteen, mixed media, $135 \times 170 \times 15 \mathrm{~cm}, 1968-1969$. (c) Ernest Edmonds) This construction was made partly by using a computer program to solve the problem of how to arrange the 20 individual pieces. 


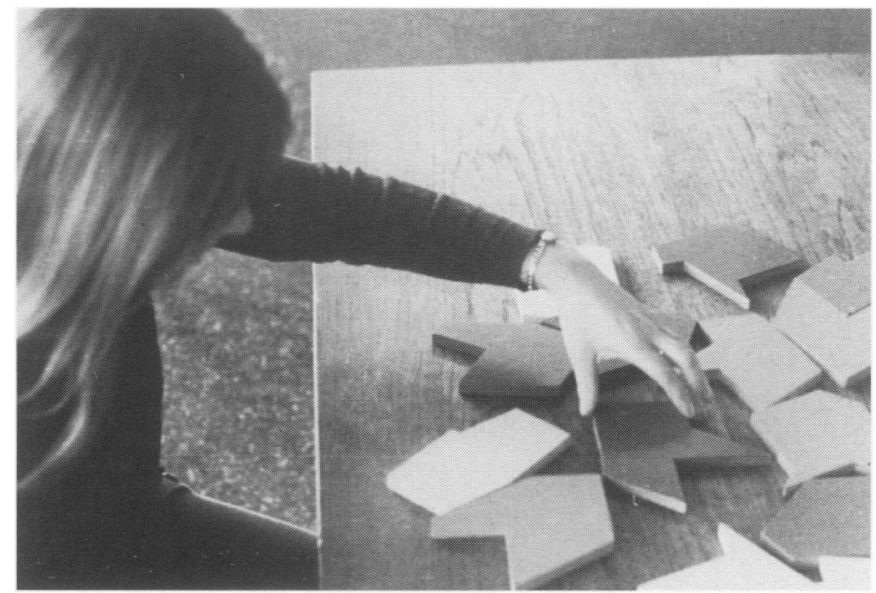

Fig. 2. Jigsaw, wood, $43 \times 43 \times$ $1 \mathrm{~cm}, 1970$. (@) Ernest Edmonds) A visitor works with the rearrangeable pieces in the exhibition Invention of Problems II, at Lancaster Polytechnic, U.K., 1970.

works, as is common today with the enormous growth of the Internet [6].

My work continued to explore these issues, but in the mid-1970s, I produced static work in which colors and shapes coexisted in spaces determined by rules similar to those used in my earlier work. Hence, I used co-existence in a number of ways but, in particular, as a substitution for a full treatment of time. So, rather than making my work dynamic, with different forms at different times, I made the different forms co-exist. Among these works were a number of pieces using a simple grid of $3 \times 3$ squares, with characteristics that propagated from "seed" squares by row, column or diagonal according to the particular rule being employed. Thus, I employed rules about how things might co-exist and how decisions of this kind might be distributed across a given work.

In the early 1980 s, it became clear that many of the problems I had addressed to that point could indeed be solved by moving from static to time-based work. At the same time, my early conviction that computers had a special role to play in artpractice dynamics was reinforced. Thus, in 1983, I began work in digital video. The final destination of the images at that time was to be a video monitor, and they were to be synthesized by computer using modern graphics techniques. Historically, the use of computers in constructive art had mostly been in the production of static objects or series of objects. Time-based work existing on a screen had generally been closer to surrealism. In any case, nearly all of this work had been geometry-based, built up with lines, polygons, fractals, etc. In this approach, abstractions are transformed into concrete images. Because my need was to construct work to be realized on a screen, it was necessary to take a different course, one that enabled me to work much closer to the reality of the image on the screen. The process I would use is known as pixel- or raster-based graphics.

The first work that I showed in this video series was Fragments, which I included in my exhibition Duality and Coexistence, at Exhibiting Space, London, 1985. This work built upon my drawings and paintings of the mid-1970s and consisted of two rectangles forming a cross. The idea, when considered statistically, was very simple. Each rectangle could either be black or white; where they overlapped, they could combine to form a black or white area according to one of four possible logical rules. The complexity of the work was in how it changed in time, and in this respect it certainly encouraged me in striving towards an earlier dream of making films [7].

My later video constructs also used color, once the technology was reliable enough in that respect (Fig. 3). Since 1990, I have undertaken a further step: The basis in time of the video constructs made it natural to consider incorporating music. The use of an underlying generative structure made this link even more interesting because of the use of structure in music. I have developed video construct pieces with both JeanPierre Husquinet and Maddy Aldis in which musicians perform together with a video projection system in unified visual and musical works.

The developments traced above have formed the basis of four prints, presenting documents and images that were key to the conceptual developments indicated. They are discussed in turn below.

\section{FOUR NOTES: FOUR CONCEPTS IN FOUR DECADES}

These four notes are based on early documentation representing four different conceptual steps using computer technology. They each consist of a set of scanned archival documents together with appropriate images and a brief descriptive factual statement about the work. I discuss each one in turn.

\section{Notes on Nineteen}

The print Notes on Nineteen records the use of a computer program, which I wrote in 1968, as a problem solver. The role of the computer was to facilitate the solution of a well-defined problem that was very hard to solve by hand or analysis. This was because a program could be

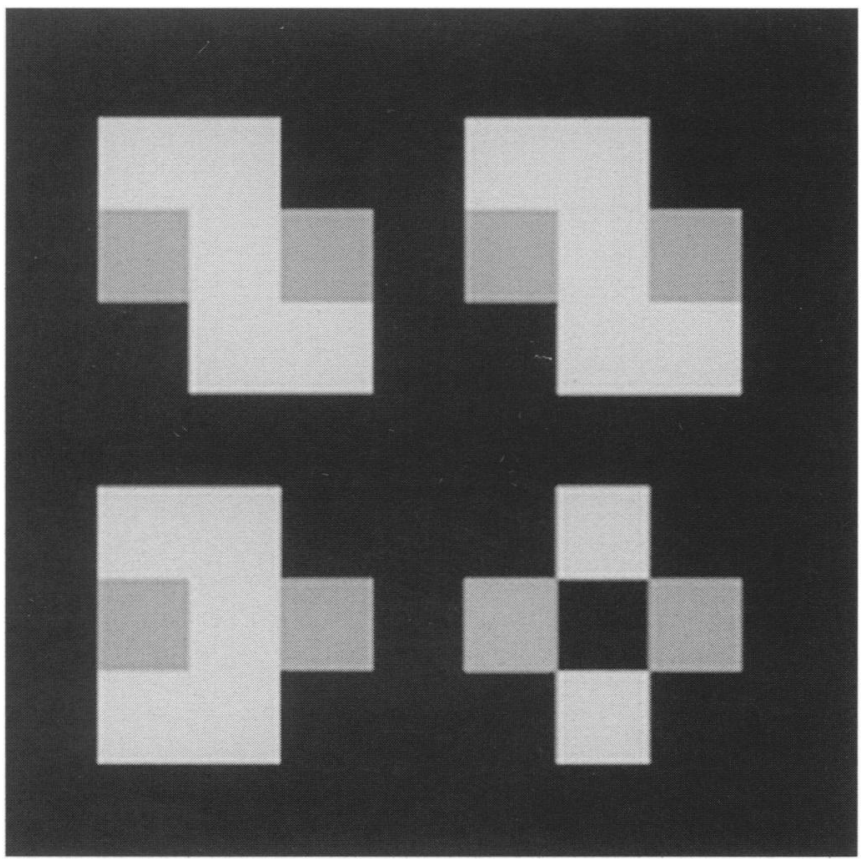

Fig. 3. From Sydney (one), Iris print, 60 $\times 60 \mathrm{~cm}, 1999$.

(C) Ernest Edmonds) This print is based on a still from the video construct Sydney, which added color changes to particular time-based features. 


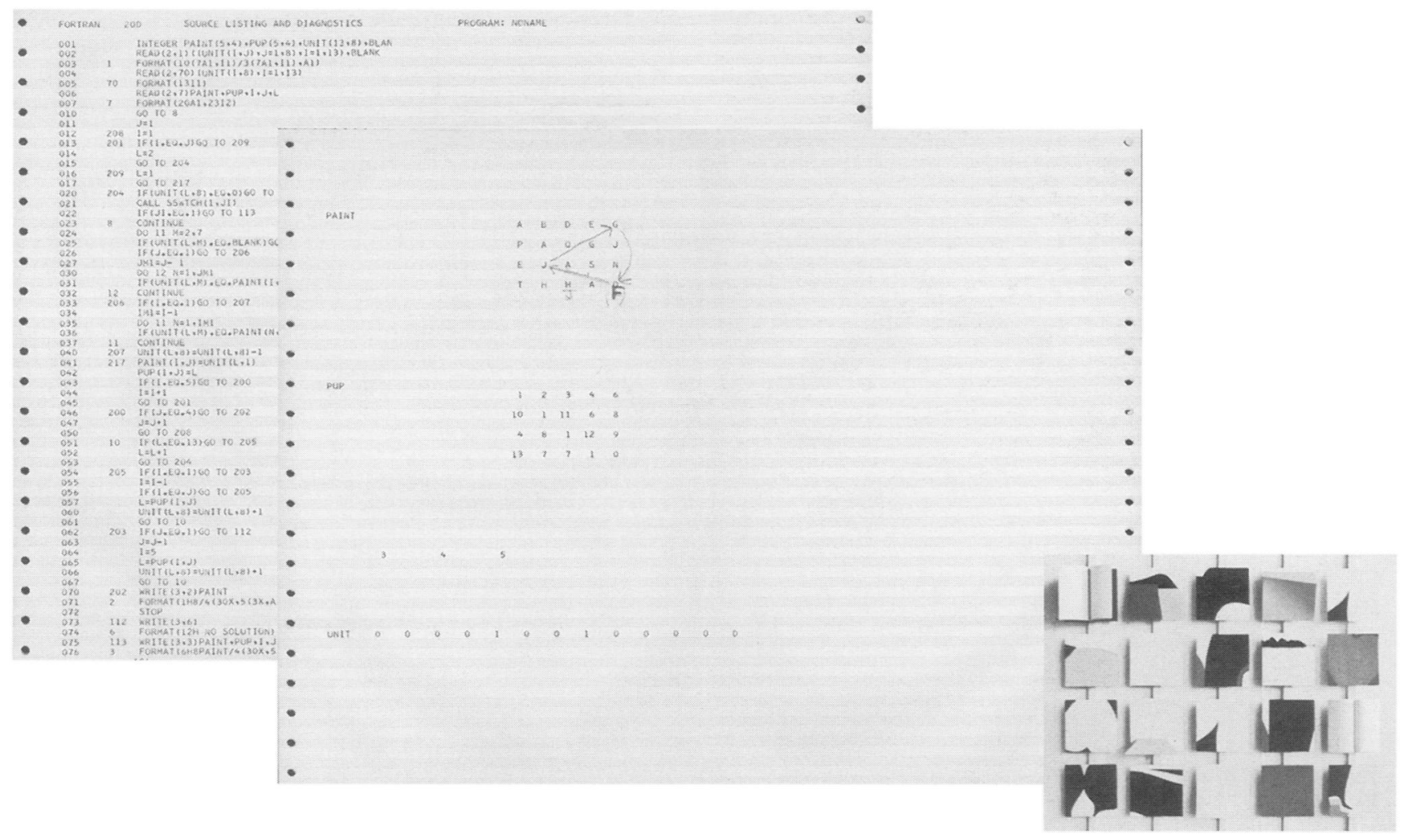

Fig. 4. Notes on Nineteen, Iris print, $50 \times 70 \mathrm{~cm}, 2000$. (@ Ernest Edmonds) This print combines scanned notes and working documents with the results, providing a documented view of the work on Nineteen.

written that searched for the problem's solution. In this case, I used the computer program in order to try to structure the work according to a set of pre-defined rules.

This earliest Notes print (Fig. 4) includes a picture of the original version of Nineteen, which incorporated many different images, drawn from things that I was doing over the previous decade or so. At that point I was moving away from figurative work. My work was becoming abstract, in the general constructivist sense of geometric abstract visual art with no representational component [8].

I needed to make that change because figuration was adding complexity (of reference) to something that was already complex enough for me. I was trying for a simpler style, not to avoid complexity but to reduce a given problem to something that I could cope with. This helped me progress as an artist. I was deciding to simplify things somewhat and to use the model that had come to me through constructivism, especially through $D e$ Stijl. The simplification included binary codes, horizontal and vertical lines, very limited palettes, etc. The complexity lay in the relationships that could be built up from the limited palette. As I understood that better I could hope to add further complexity later.
I called the construction Nineteen because it was the nineteenth painting I had done in a series. I was trying to make an arrangement of items and images that represented what I had been doing. However, I did not want the work itself to have an overall structure that dominated the individual elements. For example, two elements in the works look the same, but if they had been next to each other, they would have become a dominant part of the work. That would have been a bad idea. I came to use a computer program because I could not find a way of laying the elements out that avoided problems of that kind. I literally could not do it. On the other hand, an appropriate computer program could simply search through all possible arrangements in order to find one that met my needs.

I wrote the program in FORTRAN in 1968. It was exhibited at Leicester Polytechnic, England, around then. Its second showing was in 1976, then it was pretty much destroyed by the caretakers taking down the exhibition. Andy Dent recently made a re-construction for the exhibition Constructs and ReConstructions [9].

\section{Notes on Communication Games}

This Notes print, second in the series of prints, records the use of electronics to build a network "communication" system. It represented one of the earliest attempts to build an electronic interactive art piece in which the interaction took place between people through the system. In this case, the participants became engaged in a process where they tried to impose a structure, or order, on the pattern of events that they experienced.

The Notes on Communication Games print is based upon material from the early 1970s (Fig. 5). At that time, I was developing the idea of works that would enable people to interact with one another through technology. I was very interested in language and learning, especially in how very young people learned. What was interesting there was not how they were taught, because a 1-week-old child cannot be taught, for example, "the Battle of Hastings was in 1066." They learn through experience. The trouble with language is that one cannot tell things to people before they have ability in language. Otherwise, telling is not possible. We can use signs, but how do we know what the signs mean? Do we just pick them up by some kind of primitive understanding? A similar issue arises in experiments with chimpanzees, in which they are given tablets with symbols and learn to communicate through them. The learning comes from the experience of relating to the symbols. 

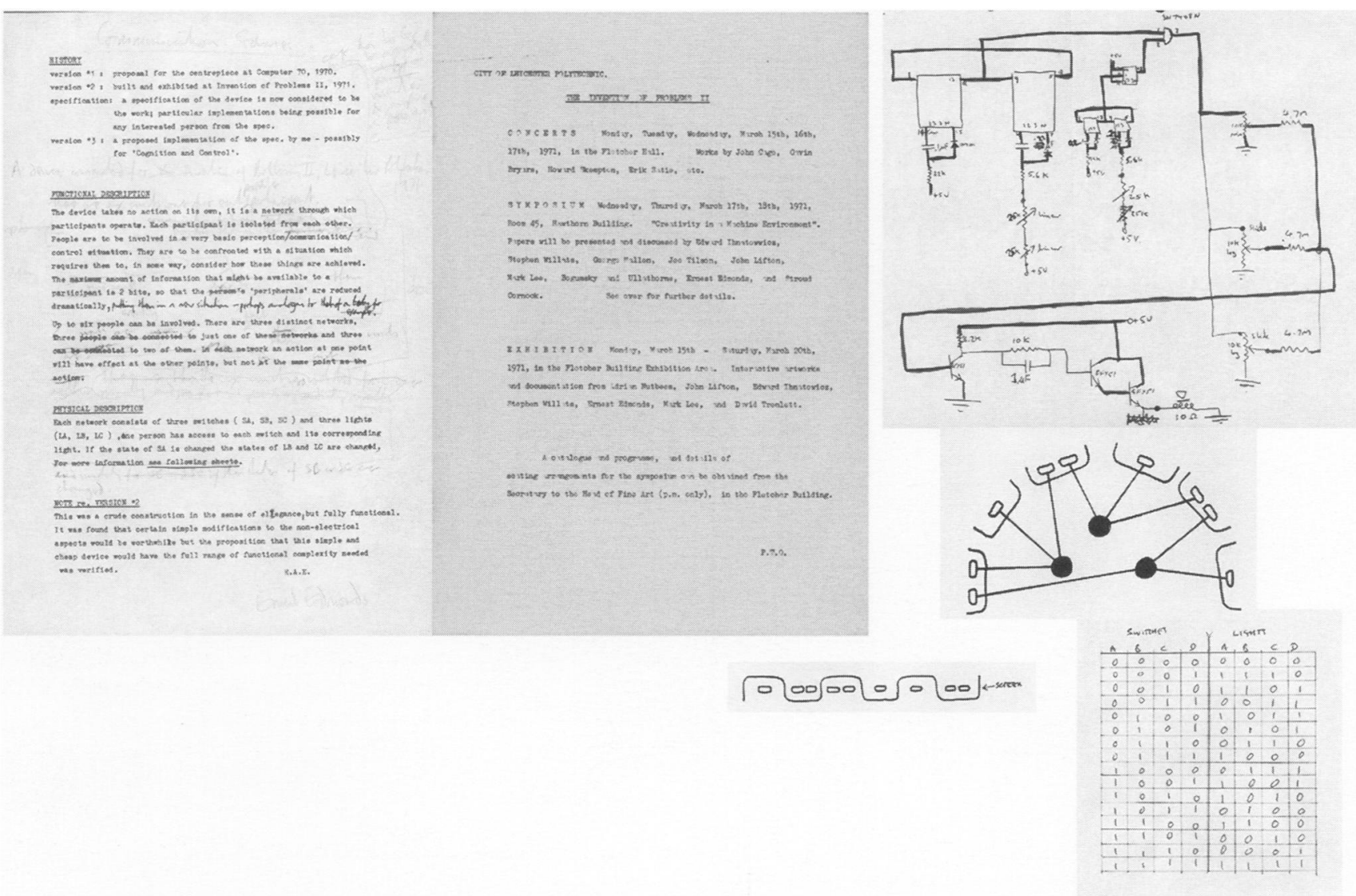

Fig. 5. Notes on Communication Games, Iris print, $50 \times 70 \mathrm{~cm}, 2000$. (৫ Ernest Edmonds) This print documents the work on Communication Games.

They are not told what the symbols mean; they create that meaning through their experiences. This is the start of some kind of primitive language process.

I conducted early experiments using electronic technology to provide a way for people to communicate. People would start to see patterns and to see how particular things might happen. Thus they would respond to particular patterns and so in a simple way communicate. I started with about 20 participants and eventually, after some experiments, cut down to just three. With larger numbers it had proved hard to obtain the desired sense of communication, but three was just right.

One might ask, If this work was modeled on young infants' communication, did participants find it rather minimal? However, the whole point was that they were confronted with something much like what an infant is confronted with, which, to the infant, is presumably very complex. There was no real explanation or story. There was no script saying what to do next. There were no instructions that people could read to find out what they were meant to do. This was not meant to illustrate research work on new infants. It was used as inspiration for a new form of artwork. The art was in the interaction between people through the system. It was a network communication concept developed well before the World Wide Web. The functionality of the device, how the interaction worked, was the key element. How it was made manifest as an object was not, to my mind, the central issue (see the notes in Fig. 6).

I made several versions, three of which were shown in exhibitions. On the whole, the responses were quite good, but the first exhibition version, which had six participants and three networks, turned out to be so confusing that people could not perceive any patterns in the behavior. I then reduced the exhibition so that it used only one of the three networks. I found that just having one network with three people was the most effective choice: It was simple enough for people to see patterns. I finally made a sound version, which also had three participants.

\section{Notes on Video Constructs}

This Notes print records the use, from the early 1980s, of a computer as a logicbased generative device to make timebased abstract digital video. In this case, the underlying logic is used to provide a structure in time, which is the basis of the generation of the works.

In 1980 I started writing notes about making what became my digital video constructs (Fig. 7). The first one with which I was satisfied was shown in London in 1985. The key idea was to use the computer to generate time-based abstract work from logical descriptions. I used Logic programming this time, rather than the earlier FORTRAN, to describe structures in time and have the computer use this logic to generate the sequence of images [10].

For this work, the key point about logic is that it is not procedural. It is declarative-i.e. we simply express what must be the case and what must not be the case. It is simply a set of assertions (e.g. this mark should be blue, green or whatever; if one is blue, then there must not be another blue; if a blue is on a row then there must not be another blue on the same row, or perhaps there must be another blue on the same row). In effect, logic programming provides an executable, problem-solving interpretation of mathematical logic. We are able to define an underlying structure in a logic programming language and then ask the com- 


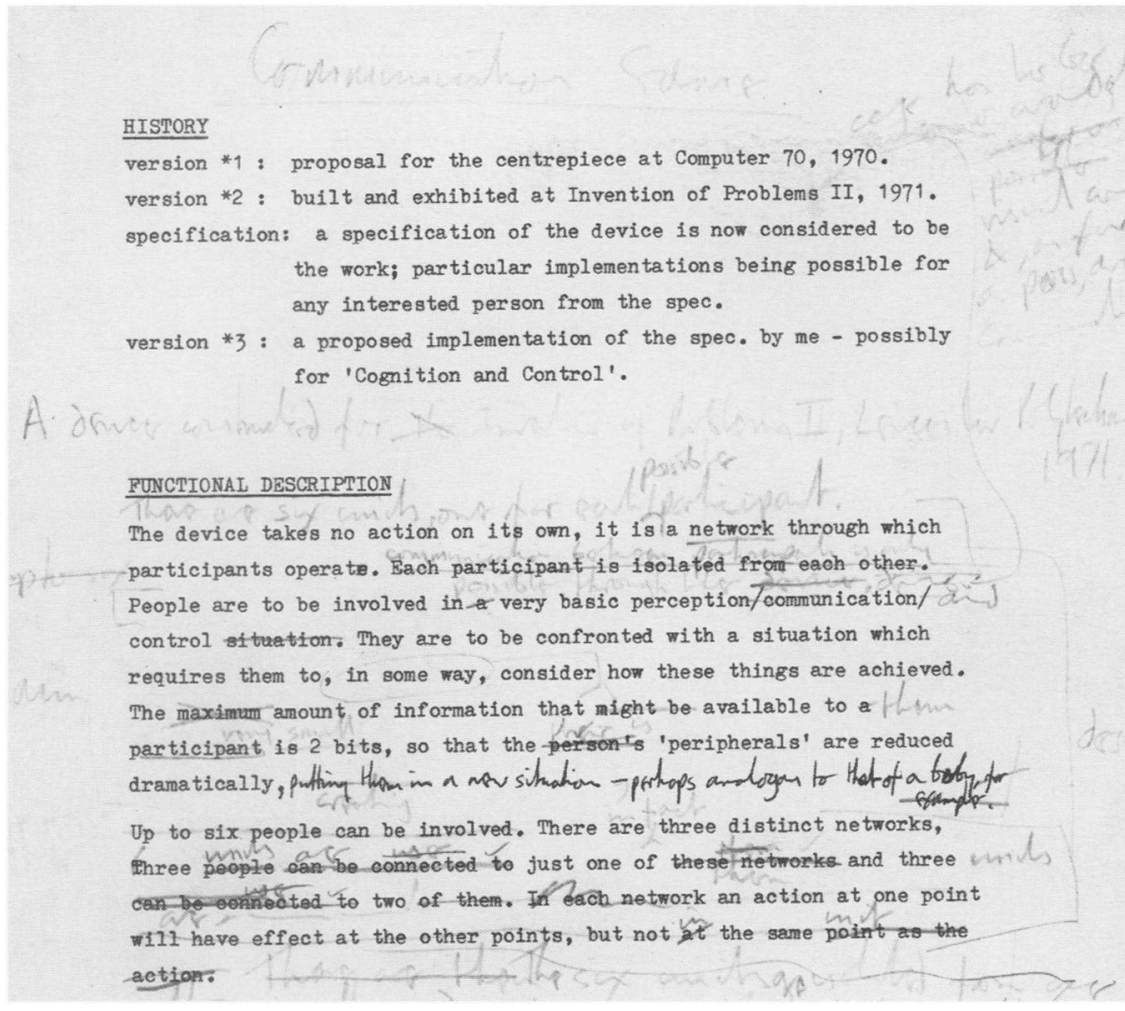

Fig. 6. Notes on Communication Games (detail). Original notes on the Communication Games concept, which show some of the development of the ideas. puter to automatically find solutions to given problems that conform to that structure.

The structure of the logic has two parts. The first is a set of statements, or rules, that define what must and must not be the case. One can define these in any form that one likes. The other part of the structure is something called an inference engine, which is, in logic programming, what takes the rules and applies them in a search for satisfactory outcomes. Hence, the inference engine will drive what happens next, because it will determine the order of the search of the problem space. However, one sees the search played out in time as the engine covers the problem space, trying out different ways of satisfying the rules.

This kind of generative program could be used in many ways, not just to create artworks. However, I do not think that anyone else had, in the early 1980s, used it for creating artworks.

I wanted to create a set of structures underpinning the work. What I tried to do was very complex and some of it took a very long time. I did not want to make the structures like cartoons, painted one frame at a time. I wanted instead to work

Fig. 7. Notes on Video Constructs, Iris print, $50 \times 70 \mathrm{~cm}, 2000$. (๑ Ernest Edmonds) This print documents the work on video constructs.

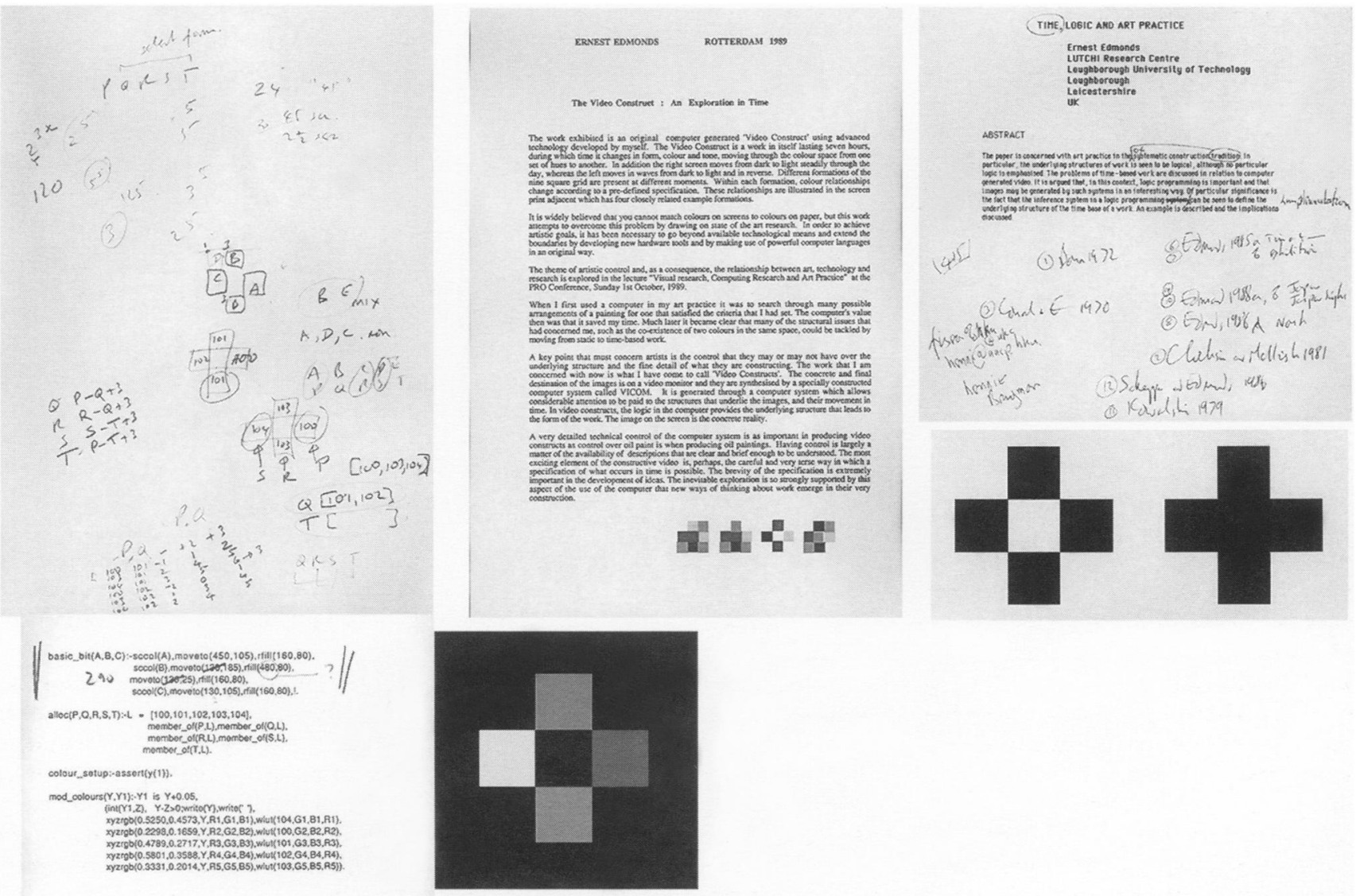




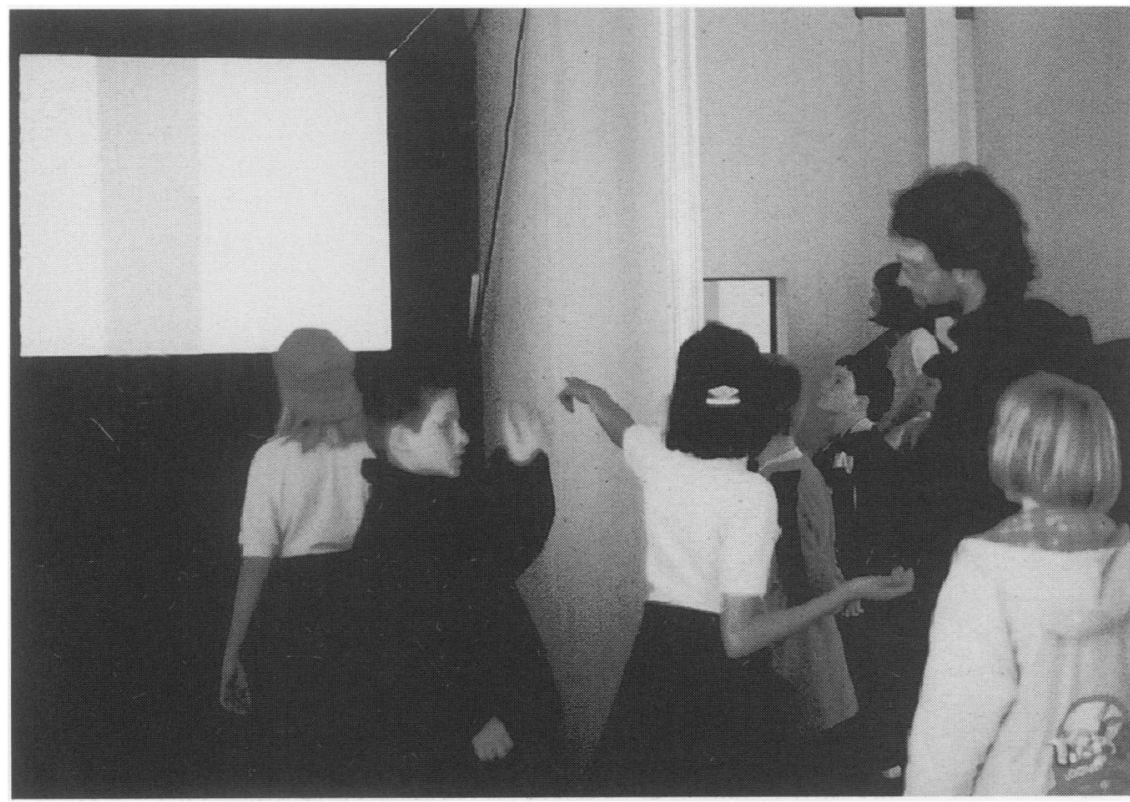

Fig. 8. Corbière, video construct (projected) in exhibition, $74 \times 99 \mathrm{~cm}, 2000$. (๑ Ernest Edmonds) Visitors look at the work in the Constructs and Re-Constructions exhibition.

from a structure's underlying rules and find a way to generate its implied results. One advantage of this approach was that I could actually try out different rules quite easily. I could use a rule, look at the the question of predictability? Well, the process is obviously not random. In fact, it is completely predictable, but, nevertheless, it is full of surprises. For example, I do not necessarily know how it will appear to the viewer.

The individual images are very simple. It is the sequence of colors and forms that contains the most complexity. There is a clear sense of order, but at the same time it is quite hard to anticipate what is going to happen next. That is, in a sense, what one experiences in most art; but, especially when we experience good art, we are not actually fundamentally surprised by what we experience, although moment by moment we are.

An interesting thing about my latest piece is that it is not hung on the wall at all. It is projected onto a sheet of freehanging plastic. The choice of colors and the lines between the bands are softer than in the earlier work, and the whole thing hangs in space (Fig. 8).

result, decide that it was not so interesting and then try a different rule or set of rules.

In productivity terms, the advantage of these structures is clear, but what about

\section{Notes on Correspondences}

The print Notes on Correspondences records the use of a computer to generate video constructs as above, but these constructs

Fig. 9. Notes on Correspondences, Iris print, $50 \times 70 \mathrm{~cm}, 2000$. This print combines a view of the work on incorporating music with video constructs.

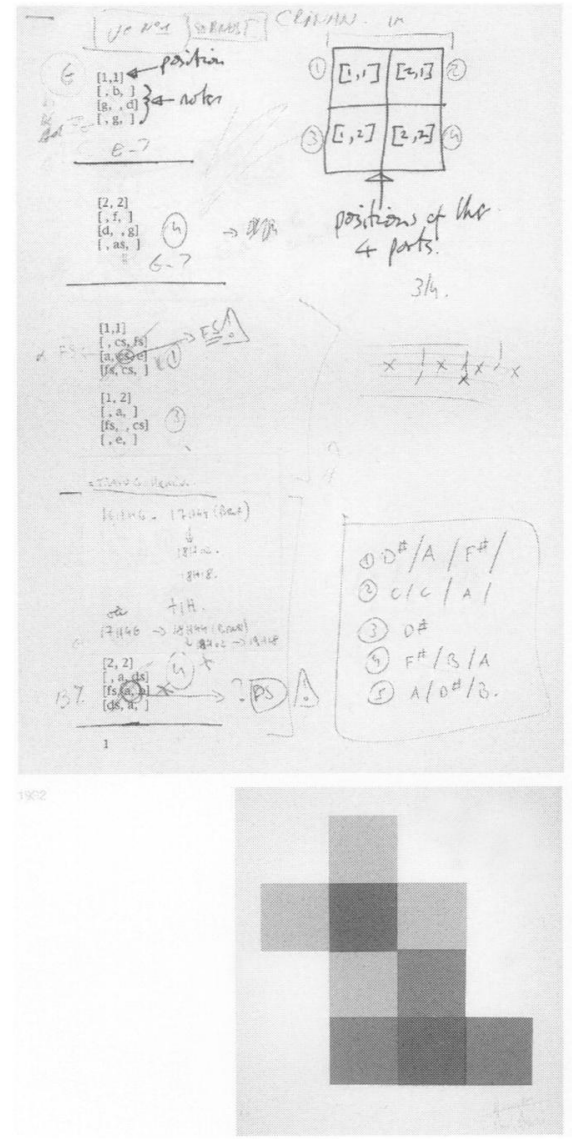


are now closely intertwined with music. In this work, the images appear as musical instruments, but their output is visual. In this case, an underlying structure is used to unify vision and sound. In the case of each "instrument," the appropriate structural elements are mapped into given sounds or images.

This is the fourth of the notes and represents my most recent work (Fig. 9). The work started in 1990 but has undergone new developments in 1999 through my collaboration with the composer Maddy Aldis. This work follows directly from the video constructs. This time, however, instead of solely visual sequences, we generate visual and musical sequences as a unified work. In one, for example, a visual sequence of images and a violin work together as if they were two instruments. One happens to generate sound, and one happens to generate visual images. They play together just as two instruments might in a duet. The new problem posed in these works is how to relate the visual structures to the sound structures. I do not claim to have resolved this difficulty, but my goal is to find some structure with which we can map both the image and the sound.

\section{REMARKS ON THE ROLE OF STRUCTURE}

The computer, and in particular the use of such programming approaches as logic programming, provides a significant enhancement to our ability to handle and consider the underlying structures of artworks and art systems in the many forms that they may take.

The notion of structure as used here implies something recoverable, in the sense that it is possible to look at an end result and determine the structures that gen- erated it. It has a clear structure, and being clearly predictable its structure is highly constrained. That nevertheless does not mean that it is boring in the sense that one actually knows what is going to happen or how a given organization works. In the example of video constructs, the explicitly determined part is the generative device in the program. However, the whole point of the process is the actual output in the generation of the visual sequence, the images.

In one case above, Notes on Nineteen, I use the computer program to try to structure the work according to some predefined rules. In the next, Communication Games, the participants become engaged in a process in which they try to impose a structure, or order, on the pattern of events that they experience. In video constructs, the underlying logic is used to provide a structure in time as a basis of the generation of the works. In the correspondences, an underlying structure is used to unify vision and sound. In the case of each "instrument," the appropriate structural elements are mapped onto given sounds or images.

In the work discussed above, while the conceptual developments are the key issues, the role of the technology in encouraging, enabling and inspiring them has been central.

\section{Acknowledgments}

Part of this paper draws upon an earlier publication [11]. The author is grateful to Mesures. Discussions with Linda Candy were important in drawing out the ideas expressed above. Any errors or confusions are, nevertheless, the author's responsibility.

\section{References and Notes}

1. S. Bann, Introduction, Systems (London: Arts Council of Great Britain catalogue, 1972) pp. 4-14.

2. E.A. Edmonds, Constructs and Re-Constructions, Loughborough University Gallery exhibition, May
2000. Web site: <http://www.ernestedmonds. org.uk>.

3. Charles Biederman, A Retrospective Exhibition (London: Arts Council of Great Britain catalogue, 1969).

4. E.A. Edmonds, "Independence of Rose's Axioms for M-Valued Implication," Journal of Symbolic Logic 34 (1969) pp. 283-284.

5. Participation and interaction are discussed in $\mathrm{S}$. Cornock and E.A. Edmonds, "The Creative Process Where the Artist Is Amplified or Superseded by the Computer," Leonardo 6, No. 1, 11-15 (1973).

$\rightarrow$ E.A. Edmonds, "Art Systems for Interactions between Members of a Small Group of People," Leonardo 8, No. 3, 225-227 (1975).

7. E.A. Edmonds, "Logic and Time-Based Art Practice," Leonardo, Electronic Art Supplemental Issue, 19-20 (1988).

8. G. Rickey, Constructivism: Origins and Evolution (George Brazillier, 1967).

9. Bann [1].

10. R. Kowalski, Logic for Problem Solving (Amsterdam: North-Holland, 1979).

11. E.A. Edmonds, "Vers 'Vidéo Constructs,'” Mesures Art International 3 (Liège, Belgium: Mesures, 1989).

Ernest Edmonds has used computers in art practice since 1968, his latest one-person exhibition being Constructs and Re-Constructions, Loughborough University Gallery, May 2000. His work has concentrated on logic-based generative digital videos known as video constructs. He first exhibited a video construct in London in 1985 and has since shown them, and related works, in Moscow, Sydney, Rotterdam, Liège, Vervier, Budapest, Koblenz and elsewhere. He has more than 150 publications. Edmonds was leader of the U.K. DTI's mission to Japan, The Interaction of Art and Technology. He is a member of the U.K. Arts and Humanity Research Board's Visual Arts and Media research panel and the ATR Art and Technology Advisory Committee, Japan. He is also Chairman of the Creativity $\mathcal{E}^{\circ}$ Cognition conference series and is Director of the Creativity and Cognition Research Studios, Loughborough University, U.K. 